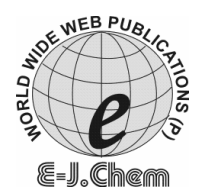

http://www.e-journals.net
ISSN: 0973-4945; CODEN ECJHAO

E-Journal of Chemistry 2010, 7(3), 775-778

\title{
Synthesis Characterization and Antimicrobial Activity of Metal Chelates of 1, 7-Di (2-hydroxyphenyl) 1, 7 di ( $N$-methyl) aza-1, 3, 5 heptarine-3-ol hydrochloride
}

\author{
NALIN P. PATANI* and M. V. HATHI \\ *C. U. Shah Science College, Ahmedabad-380014,Gujarat, India. \\ R. R. Mehta College of Science, Palanpur-385001, Gujarat, India. \\ nppatani@yahoo.co.in
}

Received 7 October 2009; Revised 17 December 2009; Accepted 10 February 2010

\begin{abstract}
The Schiff base complexes derived from 2-furancarboxaldehyde and $N$-methyl-2-amino phenol have been prepared and characterized using several physical techniques, like elemental analysis, thermogravimetric analysis, magnetic moment measurements, infrared and resonance spectra. $\mathrm{N}$-Methyl-2-amino phenol was condensed stoichiometrically with 2furancarboxaldehyde in presence of methanol. The resulting 1,7-di(2hydroxyphenyl) 1,7 di( $N$-methyl) aza-1,3,5 heptarine-3-ol hydrochloride was characterized by elemental analysis and spectral studies. The transition metal complexes of $\mathrm{Cu}^{2+}, \mathrm{Zn}^{2+}, \mathrm{Ni}^{2+}, \mathrm{Co}^{2+}$ and $\mathrm{Mn}^{2+}$ of the synthesized complexes were prepared. Metal ligand (M:L) ratio, IR, reflectance spectral studies, magnetic properties and antimicrobial activity of the synthesized complexes and its metal complexes were carried out.
\end{abstract}

Keywords: 2- Furancarboxaldehyde, $N$-Methyl-2-amino phenol, Metal complexes, Magnetic moment, Antifungal activities.

\section{Introduction}

2- Furancarboxaldehyde is well known as an analytical reagent ${ }^{1,2}$. Its various derivatives ${ }^{3}$ are also useful. The complexes obtained from ligands having methyl, ethyl, nitro as functional group ${ }^{4}$ have been investigated exhaustively. Receiving impetus from the above observation and continuation of our research program, it was thought to undertake such view. The present communication describes the synthesis and characterization of 1,7-di(2hydroxyphenyl) 1,7 $\mathrm{di}(\mathrm{N}$-methyl)aza-1,3,5 heptarine-3-ol hydrochloride and its complexes 
with $\mathrm{Cu}^{2+}, \mathrm{Zn}^{2+}, \mathrm{Ni}^{2+}$ and $\mathrm{Co}^{2+}$ also antimicrobial activities of these complexes. This work is illustrated in Scheme 1.

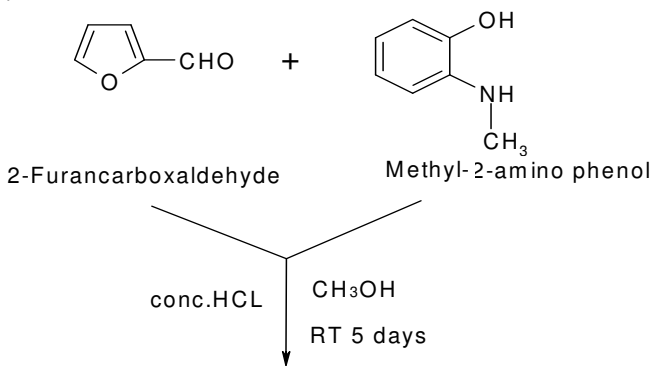

\section{Experimental}

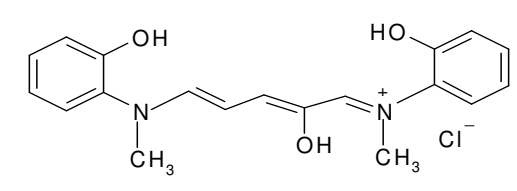

SSL-2

2-Amino phenol was obtained from local dealer in market. The metal salts and other chemicals used were of analytical grade. To a solution of $(0.1 \mathrm{M}) \mathrm{N}$-methyl-2-amino phenol in methanol, a solution of 2- furancarboxaldehyde $(0.05 \mathrm{M})$ in methanol was added drop wise within 20 minutes. Then $9 \mathrm{~mL}$ conc. $\mathrm{HCl}$ was added slowly with maintaining the room temperature. The mixture was kept aside for five days with occasional stirring. The resulting dark violet compound was filtered and washed by methanol and then with ether ${ }^{5}$. Finally it was air-dried. The yield was about $63 \%$. The $\mathrm{Cu}^{2+}, \mathrm{Zn}^{2+}, \mathrm{Ni}^{2+}$ and $\mathrm{Co}^{2+}$ metal ion complexes of ligand SSL-2 were prepared using the following procedure.

The solution of $25 \mathrm{~mL}$ disodium salt containing $0.01 \mathrm{M}$ ligand was taken, then each ligand was added drop wise to a solution of $0.005 \mathrm{M}$ cupric nitrate hexahydrate in 100 of water with rapid stirring. The $\mathrm{pH}$ of the resultant solution was 4.5 . The solid mass was precipitated out. It was allowed to settle down then digested on water bath at $70{ }^{\circ} \mathrm{C}$ for about $2 \mathrm{~h}$. The solid mass was filtered, washed with 1:1 mixture of water-ethanol and finally with acetone and air-dried, the resulting yield was $70 \%$. The resulting complex was powdered well and further dried at $70{ }^{\circ} \mathrm{C}$ over a period of $24 \mathrm{~h}$. The details of the elemental analysis of the complexes are given in Table 1. Ligand 1,7-di(2-hydroxyphenyl)1,7 di ( $N$-methyl)aza-1,3,5 heptarine-3- ol-hydrochloride (SSL2) and its synthesized complexes were insoluble in water, slightly soluble in methanol, ether, chloroform and other organic solvents. They were soluble in DMF. All the samples were measured by elemental analyzer Thermo Finiggan 1101 Flash EA ${ }^{6}$. IR spectra of SSL-2 and its metal complexes were scanned on Nicolate 760 FTIR Spectrophotometer in $\mathrm{KBr}$. The metal content of the metal chelates by decomposing a weighed amount of each metal complexes were analysed followed by EDTA titration as reported in literature ${ }^{7}$. Magnetic susceptibility measurement of all metal complexes was carried out at room temperature by the Gouy method ${ }^{8}$ The values are given in Table 2. Mercury tetrathiocynatocobltate(II) was used as a calibrant ${ }^{9}$.The reflectance spectra of the metal chelates in the visible region were recorded against $\mathrm{MgO}$ on Backman DK 2A Spectrophotometer (Figure 1). The antimicrobial activities of the synthesized metal complexes were carried out by cup-plate method ${ }^{10}$. All the samples were monitored against various fungi following the method reported in literature ${ }^{11}$. 


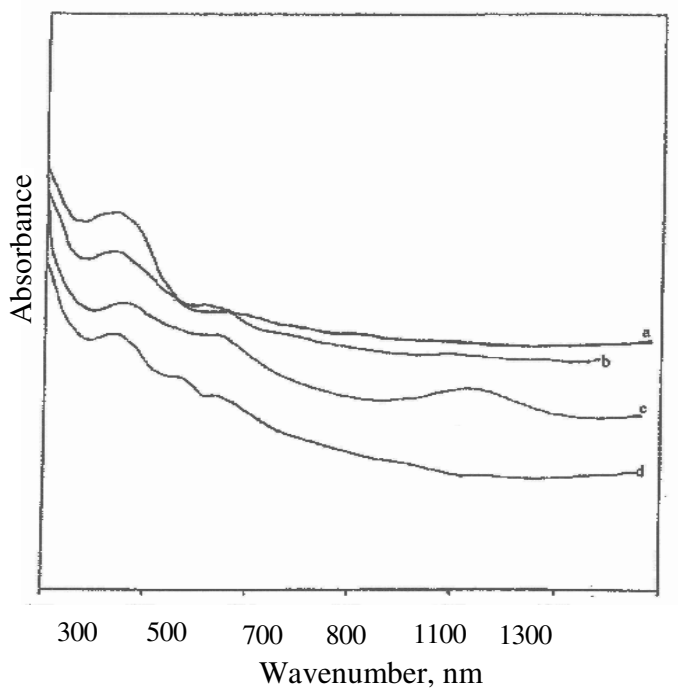

Figure 1. Reflectance spectra of SSL-2 metal complexes (1) SSL-2 $\mathrm{Cu}^{2+}(2) \mathrm{SSL}-2 \mathrm{Ni}^{2+}$ (3) SSL-2 $\mathrm{Co}^{2+}(4) \mathrm{SSL}-2 \mathrm{Mn}^{2+}$.

\section{Results and Discussion}

1,7 $\mathrm{Di}(N$-methyl)aza-1,3,5 heptarine-3-ol hydrochloride was dark violet powder. The result of elemental analysis of ligand is reported in Table 1 . The values are consistent with the predicted structure (Scheme 1). The IR spectra of 1,7 di( $N$-methyl)aza-1,3,5 heptarine-3-ol hydrochloride comprises the important bands ${ }^{12}$ observed at 3600 to $2600 \mathrm{~cm}^{-1}$. The IR spectra of all the chelates suggest that the formation of entire metalocyclic compound by the absence of band characteristic of free -OH group. The electronic spectrum of $\mathrm{Co}$ (II) complexes exhibits three bands around 22834, 16462 and $9222 \mathrm{~cm}^{-1}$. Which are assigned ${ }^{6} \mathrm{~A}_{1 \mathrm{~g}}(\mathrm{~F}) \rightarrow{ }^{4} \mathrm{~T}_{2 \mathrm{~g}}(\mathrm{~F}),{ }^{6} \mathrm{~A}_{1 \mathrm{~g}}(\mathrm{~F}) \rightarrow$ ${ }^{4} \mathrm{~T}_{2 \mathrm{~g}},{ }^{6} \mathrm{~A}_{1 \mathrm{~g}}(\mathrm{~F}) \rightarrow{ }^{4} \mathrm{~T}_{2 \mathrm{~g}}(\mathrm{P})$ respectively in octahedral field ${ }^{13}$. The magnetic moment ${ }^{4}$ of the order is 3.76 B.M. The electronic spectra of $\mathrm{Cu}^{2+}$ metal chelate of each of the ligand may be assigned to ${ }^{2} \mathrm{~B}_{1 \mathrm{~g}} \rightarrow{ }^{2} \mathrm{~A}_{1 \mathrm{~g}}$ and charge transfer transition respectively. The electronic spectral of $\mathrm{Mn}^{2+}$ complexes were also show three bands. The examination of antifungal activity ${ }^{15}$ of SSL-2 ligands and its all chelates (Table 3) indicates that all compounds are good toxic for fungi. Out of all the compounds copper chelates is more than that of other (Table 3 ).

Table 1. Analytical data of the metal chelates of SSL - 2.

\begin{tabular}{|c|c|c|c|c|c|c|c|c|c|c|}
\hline \multirow{3}{*}{$\begin{array}{l}\text { Molecular } \\
\text { formula }\end{array}$} & \multirow{3}{*}{$\begin{array}{c}\text { Yield } \\
\%\end{array}$} & \multirow{3}{*}{$\begin{array}{l}\text { Mol. } \\
\text { Wt. }\end{array}$} & \multicolumn{6}{|c|}{ Elemental analysis } & \multirow{2}{*}{\multicolumn{2}{|c|}{ Metal, \% }} \\
\hline & & & \multicolumn{2}{|c|}{$\mathrm{C} \%$} & \multicolumn{2}{|r|}{$\mathrm{H} \%$} & \multicolumn{2}{|c|}{$\mathrm{N} \%$} & & \\
\hline & & & Cald. & Found & Cald & Found & Cald. & Found & Cald. & Found \\
\hline $\mathrm{C}_{19} \mathrm{H}_{20} \mathrm{~N}_{2} \mathrm{O}_{4} \mathrm{Cu}^{2+} 2 \mathrm{H}_{2} \mathrm{O}$ & 65 & 439.5 & 51.8 & 51.6 & 4.6 & 4.5 & 6.4 & 6.3 & 14.4 & 14.3 \\
\hline $\mathrm{C}_{19} \mathrm{H}_{20} \mathrm{~N}_{2} \mathrm{O}_{4} \mathrm{Mn}^{2+} 2 \mathrm{H}_{2} \mathrm{O}$ & 67 & 431 & 52.9 & 52.7 & 4.6 & 4.5 & 6.5 & 6.4 & 12.7 & 12.6 \\
\hline $\mathrm{C}_{19} \mathrm{H}_{20} \mathrm{~N}_{2} \mathrm{O}_{4} \mathrm{Ni}^{2+} 2 \mathrm{H}_{2} \mathrm{O}$ & 57 & 435 & 52.4 & 52.3 & 4.6 & 4.5 & 6.4 & 6.3 & 13.5 & 13.4 \\
\hline $\mathrm{C}_{19} \mathrm{H}_{20} \mathrm{~N}_{2} \mathrm{O}_{4} \mathrm{Co}^{2+} 2 \mathrm{H}_{2} \mathrm{O}$ & 62 & 435 & 52.4 & 52.4 & 4.6 & 4.5 & 6.4 & 6.3 & 13.5 & 13.4 \\
\hline $\mathrm{C}_{19} \mathrm{H}_{20} \mathrm{~N}_{2} \mathrm{O}_{4} \mathrm{Zn}^{2+} 2 \mathrm{H}_{2} \mathrm{O}$ & 60 & 441 & 51.7 & 51.6 & 4.5 & 4.5 & 6.3 & 6.3 & 14.7 & 14.6 \\
\hline
\end{tabular}


Table 2. Experimental data of magnetic moment of metal chelates of SSL- 2.

\begin{tabular}{ccccc}
\hline $\begin{array}{c}\text { Metal } \\
\text { Complex }\end{array}$ & $\begin{array}{c}\chi_{\mathrm{g}} \times 10^{6} \\
(\mathrm{cgs})\end{array}$ & $\begin{array}{c}\chi_{\mathrm{m}} \times 10^{6} \\
(\mathrm{cgs})\end{array}$ & $\begin{array}{c}\text { Observed Magnetic } \\
\text { moment } \mu_{\mathrm{eff}}(\mathrm{B} . \mathrm{M} .)\end{array}$ & $\begin{array}{c}\text { Theoretical } \\
\mu_{\mathrm{eff}=} \sqrt{n(n+2)}(\mathrm{B} . \mathrm{M} .)\end{array}$ \\
\hline$(\mathrm{SSL}-2) \mathrm{Cu}^{2+}$ & 2.55 & 1121.89 & 1.65 & 1.73 \\
$(\mathrm{SSL}-2) \mathrm{Ni}^{2+}$ & 7.42 & 3230.72 & 2.80 & 2.82 \\
$(\mathrm{SSL}-2) \mathrm{Co}^{2+}$ & 13.39 & 5825.86 & 3.76 & 3.87 \\
$(\mathrm{SSL}-2) \mathrm{Mn}^{2+}$ & 33.84 & 14588.76 & 5.95 & 5.91 \\
$(\mathrm{SSL}-2) \mathrm{Zn}^{2+}$ & - & - & - & $\mathrm{D}^{*}$ \\
\hline
\end{tabular}

Table 3. Antifungal activity of SSL-2 and their metal complexes.

\begin{tabular}{cccccc}
\hline & \multicolumn{5}{c}{ Zone of inhibition at $1000 \mathrm{ppm} \%$} \\
\cline { 2 - 6 } Sample & $\begin{array}{c}\text { Penicillium } \\
\text { Expansum }\end{array}$ & $\begin{array}{c}F . \\
\text { Udum }\end{array}$ & $\begin{array}{c}\text { Nigras Pora } \\
\text { Sp. }\end{array}$ & $\begin{array}{c}\text { Trichoderma } \\
\text { Sp. }\end{array}$ & $\begin{array}{c}\text { Erysiphe } \\
\text { pisi }\end{array}$ \\
\hline SSL-2 & 54 & 55 & 54 & 62 & 65 \\
$(\mathrm{SSL}-2)_{2} \mathrm{Cu}^{2+}$ & 88 & 78 & 82 & 88 & 75 \\
$(\mathrm{SSL}-2)_{2} \mathrm{Mn}^{2+}$ & 62 & 70 & 74 & 68 & 75 \\
$(\mathrm{SSL}-2)_{2} \mathrm{Zn}^{2+}$ & 75 & 70 & 66 & 74 & 66 \\
$(\mathrm{SSL}-2)_{2} \mathrm{Co}^{2+}$ & 66 & 54 & 70 & 69 & 66 \\
$(\mathrm{SSL}-2)_{2} \mathrm{Ni}^{2+}$ & 54 & 58 & 78 & 45 & 64 \\
\hline
\end{tabular}

\section{Acknowledgment}

The author is thankful to Ex. Principal Dr. M. V. Hathi, R. R. Mehta Science College, Palanpur, Gujarat for providing me laboratory facility and Principal of C.U.Shah Science College for encouragement in my research work.

\section{References}

1. Bhakti, J Sci Ind Res., 1953, 114, 1213.

2. Poddar Z, Ana Chem., 1957, 154, 327.

3. Ullman`s Encyclopedia of Industrial Chem, Willey Veh., 1984, 26, 614.

4. Oster K A, and Golden M J, J Am Phrm Assoc., Sci Ed., 1947, 37, 283.

5. Vogel A I, book of practical organic Chemistry $5^{\text {th }}$ Ed, Pearson education, New Delhi, India, 2004.

6. Vogel A I, A Textbook of Quantative Analysis, $3^{\text {rd }}$ Ed., ELBS, London, 1978.

7. Radjohn N and Sujatha G D, et al., Indian J Exp Biol., 1975, 13, 286.

8. Radjohn N, Org Synthesis, coll. Vol. IV Willey \& Sons N.Y,1963

9. Lewis J and Wilkins R G, Modern Coordination Chemistry, Interscience, New York,1964.

10. Figgis B N and Lewis J, The Magneto Chemistry of Complexes in Modern Coordination Chemistry, New York, 1960.

11. Baily W R and Scott E G, Diagnostic Microbiology, The C.V Moshy Cost.Lovis, 1966, 257.

12. Nakamoto K, Infrared Spectra of Inorganic and Coordination Compounds, Wiley, New York, 1970.

13. Lever A B P, Inorganic Electronic Spectroscopy, Elsevier, New York, 1968.

14. Carlin R N and Van Dryneveldt A J, Magnetic properties of Transition Metal Compound, Spring-Verlag, NY, 1997.

15. Solanki M R, Acharya G D and Hathi M V, E Journal of Chemistry, 2009, 6(4), 1023-1028. 


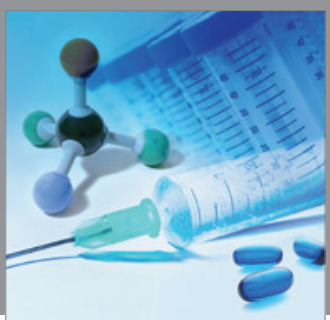

International Journal of

Medicinal Chemistry

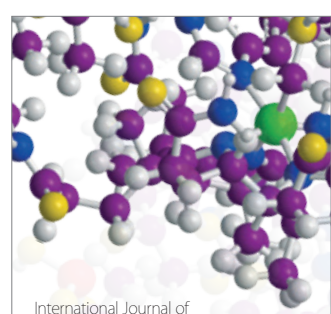

Carbohydrate Chemistry

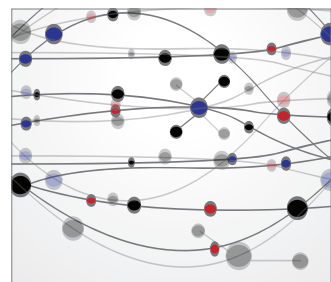

The Scientific World Journal
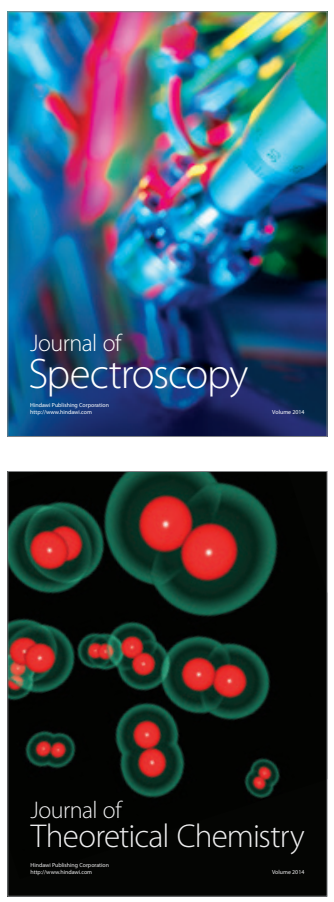
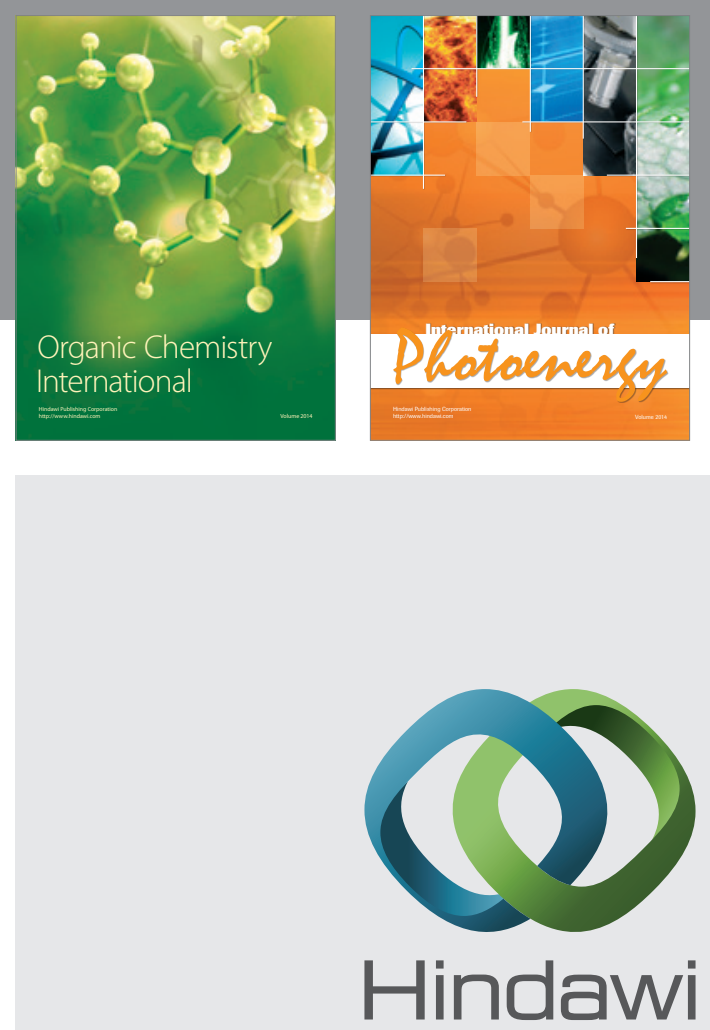

Submit your manuscripts at

http://www.hindawi.com
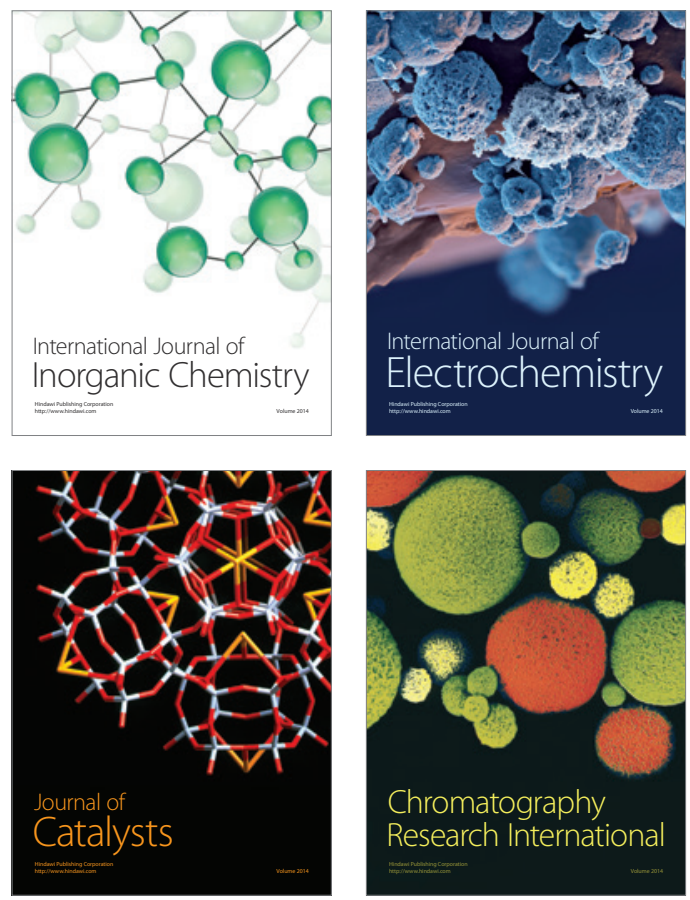
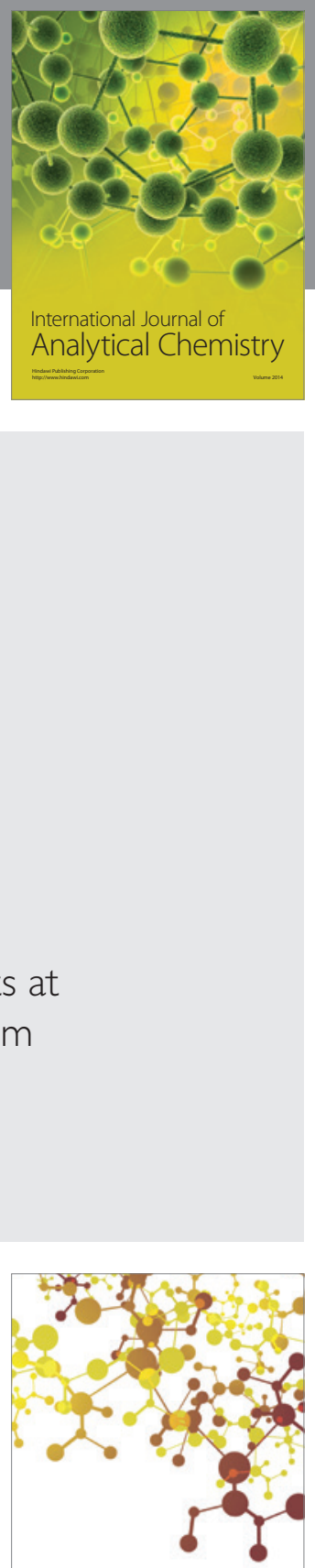

Journal of

Applied Chemistry
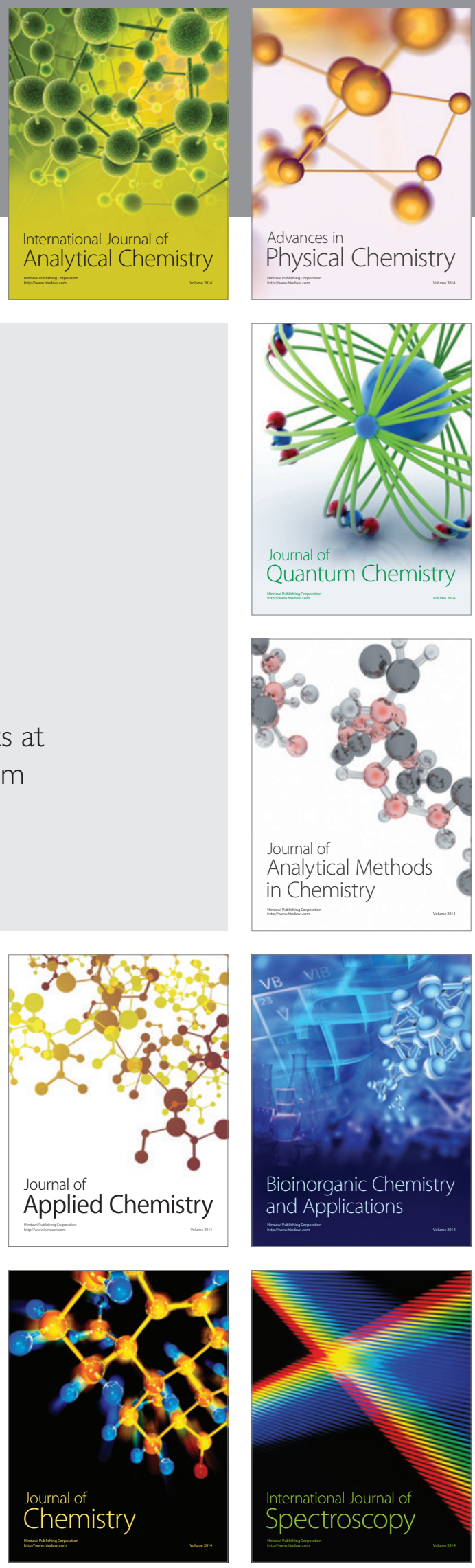